Hungarian Educational Research

Journal

\section{The Rostock model - Design and Implementation of Complex Learning Units in Elementary Schools}

Ilona Weissenfels ${ }^{26}$
2016, Vol. 6(1) 92-104

(C) The Author(s) 2016

http://herj.lib.unideb.hu

Debrecen University Press

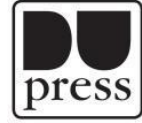

DOI: 10.14413/HERJ.2016.01.06

\begin{abstract}
The "Rostock Model" is an international didactic programme whose development and testing took place at the University of Debrecen between 2004 and 2008, with the participation of the teaching staffs of the University of Debrecen and the University of Rostock. It is a methodological toolkit for designing and creating complex, often cross-disciplinary learning units. (Schneider, 2007; 2008a; 2008b; Weissenfels, 2015). The primary aim of the programme was to develop and investigate junior school children's problem-solving thinking as well as to strengthen the social nature of learning. The study undertakes to demonstrate the theoretical concepts of the programme, namely: methods of placing learner activities in the focus and the didactic elements involved in them, conceptual approaches taking children's thinking into consideration, the possibilities involved in improving capabilities development derived from the success of cooperative work, the main directions of the development of student self-appraisal and selfrecognition resulting from this programme, the shaping of the social background of learning with understanding and its factors. The publication is a qualitative analysis and evaluation of how the above theoretical aspects manifest itself in the practice of the didactic programme.
\end{abstract}

Keywords: primary school, science education, social learning, Rostock model, science thinking

${ }^{26}$ Ilona Weissenfels, University of Rostock, Rostock (Germany), ilonaweissenfels@uni-rostock.de 


\section{Preliminary assumptions}

This model is based on the following theoretical assumptions about learning and development: children are willing to communicate and to learn new things. They have an innate desire for education. They want to learn something. Children start school with these essential properties.

Learning is an individual- constructive, social process of appropriation. Consequently, children cannot be considered to be objects in knowledge transfer. Instead, children should be looked upon as subjects of their own learning process, which is characterized by desire for instruction (imitation), for freedom (creativity) and for teamwork (cooperation). Therefore, instructive, cooperative and independent forms of learning are not competing categories but there is rather a dialectical and supplementary relationship between them. As a result, these various forms of learning should be considered in equal measure when it comes to didactic design.

Learning can be characterized as a series of long-term processes; i. e. children need time to develop ideas, to discuss and to prove them. They also need time to to think about their own concepts and to put their thoughts into words. Children need time for revision, practice and experiments. They need time for their questions and for conversations. They also need a great deal of time for playing and moving around. Consequently, learning processes at school should not be planned from lesson to lesson, consisting of small, separate units. Instead, it is favorable to choose a complex, long-term approach which also integrates cross-disciplinary elements, whenever possible.

Learning at school is a planned and goal-oriented form of learning, which takes place in a class. Teachers have to know exactly what they want to achieve in class in order to make the right decisions about how they teach. Children also need specific goals if they want to be successful learners. Therefore, when it comes to setting learning objectives, not only teachers but children should also have a say. Furthermore, these discussions with children should be properly documented, too.

In elementary school, children learn basic competences which they must be able to activate in the long run because these will be essential for advanced learning. The sign of effective and long-term learning is that children start to think in terms of general concepts. This implies an extensive network of models and generalized patterns which help children to explain and to comprehend various phenomena. There is an interaction between these models and concepts can be transferred from one model to another. 
Working with general themes which focus on essential elements of a concept, is the way to develop conceptual knowledge.

\section{Basic structure of the didactic conception Rostock model}

Treating children as independent learners means that from the very beginning, they should take an active part in organizing their own learning. Therefore, they should be involved in decisions in a clear and transparent way. This should be considered as early as in the planning stage when teachers set group specific learning objectives, think about general themes, identify essential concepts. This is also the stage when teachers make decisions about learning content, appropriate teaching and learning methods.

Each learning unit starts with an initial phase (introduction, raising awareness). The teacher discusses with the children what material they are going to cover. They set learning objectives and criteria and also develop a general theme together for the new topic. These categories are put on display in the classroom so that children can have a look at them any time.

At the beginning of the exploratory phase (elaboration), the teacher provides general cognitive guidelines by giving and justifying examples and models. Teachers should also be ready to explain these guidelines and to provide additional clarification. Children are given the opportunity to carry out practical actions with objects within a social learning context. Instruction, independent learning and cooperation are present in equal measure. The teacher motivates children to work carefully and makes sure that all constitutive activities are carried out in full. Furthermore, the teacher gives ongoing feedback and enables the qualitative assessment of learning achievements. Children use learning objectives and criteria to reflect on their activities and results.

In the concluding presentation phase, which has a monitoring function, the teacher encourages children to present their findings by using various techniques such as overviews, charts, diagrams or models. At the same time, children are asked to comment on their chosen topic in a written form and/or in an oral presentation. For example, they can write a test or give a talk.

Each learning unit ends with a reflection phase. Relying on the learning objectives and criteria, children evaluate their learning processes and achievements. They also reflect on their feelings and emotions during the activities.

Depending on the unit, the presentation phase can also follow the reflection phase. This means that teachers are free to decide which didactic function they take first. 


\section{Action-oriented didactic elements within the model}

The Rostock Model is characterized by specific action-oriented didactic elements which enable a child-friendly approach to organizing and optimizing learning and teaching activities. These elements help teachers plan, teach and analyze their own lessons.

\section{Focusing on the significance of the learning content}

Within this model, it is a fundamental didactic idea that children should take an active part in organizing their own learning. They should be involved in decisions in a clear and transparent way. As a result, at the beginning of each unit teachers discuss with children why the upcoming topic is significant: why is it important and why is it useful to learn about this topic? If one considers how the human brain works, this approach also proves to be appropriate. The brain always has some expectations about incoming information and compares these with the stimuli it receives. Consequently, learning can be enhanced if specific stimuli raise learner's awareness beforehand (Spitzer, 2004). Children (actually not exclusively) are always curious about how they benefit from learning something new (Schneider, 2003: 22). They make a kind of "cost-benefit calculation" and are willing to learn only what they think is useful for them. Consequently, teachers should select themes which children can clearly relate to and can recognize as useful for their everyday life. Children should discuss in pairs why they find it important to learn about the upcoming theme. Finally, some of the comments is written on a poster or on the blackboard, representing the various opinions of the students. The comment should be placed in the classroom so that children can see it during the entire learning process and the teacher should also refer to this sentence again and again (Clarke, 2001).

\section{Involving children in setting learning objectives}

Speaking of learning management, why is it important to set clear objectives at all? To a great extent, interest and attention are raised by expectations which correspond with learning objectives, provided children are informed about these in advance. It proves to be an effective way to keep children focused if these objectives are not exclusively looked upon as components of teachers' work but they are also deployed as learning tools within classroom.

Traditionally, it is the teachers who make decisions about learning objectives during the preparation. These decisions are based on what knowledge children should acquire, what skills and attitudes should be developed (the teachers' perspective). What is new about the Rostock model is that learning objectives are formulated in two different ways: by 
asking open questions (what is the problem? what has to be explained?) and by determining the desired outcome (what will children know, learn, discover, be able to do etc.) As for skills development and attitude formation, the teacher also sets specific goals: which general, transferable and evaluable skills are developed especially? Which essential attitude is emphasized?

If teachers want to exploit the expectations of the children as a tool for learning, it is essential but not sufficient to set learning objectives as described above. Learning efficiency increases when children

- $\quad$ know exactly what they have to do and to achieve

- can participate in decision-making and are in control of their own learning.

As for learning objectives and units, children continuously need some orientation from the very beginning. This implies that guidelines should always be visible and easy to remember. Clear objectives are like docking stations for expectations. Therefore, the learning objectives within a course unit should always be determined not only from the teacher's but also from the pupil's perspective. After the initial discussion about the significance of the upcoming unit, the teacher also discusses the learning objectives with the children: What are we expected to know and to be able to do? Goals and objectives are formulated in a clear and very specific language which is easy to understand for children (children's perspective). In order that each and every child can use these goals as a means of orientation, they are put on display in the classroom and during the learning process they serve as a constant point of reference.

\section{Working with generative themes}

It is essential to acquire comprehensive cognitive and practical concepts in order to take appropriate actions in a complex world and to cope with new situations properly. As we all know, after learning something it takes only little time to forget it. This is why it makes sense to focus on a central theme which comprises the gist of a given subject. In this context, Daniel Goleman (2008) uses the notion of memes. This concept refers to ideas and themes which spread from one human being to another, just like emotions: „Memes with particular power, like democracy or cleanliness, lead us to act in a specific way“(74). Several advanced and complex ideas are based on central, generative themes, which are characterized by transdisciplinarity and support comprehension (Blíthe, 1999).

An example: Constant dripping wears the stone away. Within the context of natural sciences, for instance when discussing a topic related to water in class, this sentence may refer to how powerful water is. Within a social context, endurance may be highlighted as a generative theme in this respect. A generative theme can be conceptualized as a pervasive theme (similar to themes in music). It constantly refers back to the essential 
theme of the unit and it also opens up new vistas enabling fresh insights again and again. When teachers work consciously with such themes, it results in a rhythmic form of learning and teaching. Generative themes vary depending on pupil's age, social and cultural background, personal interest and intellectual experience. In elementary school, proverbs, rhymes and core statements lend themselves for such themes. Generative themes are mainly thought-provoking ideas and impulses for attitude formation.

Elementary school students are very much responsive to such themes and they refer back to these themes in their line of argumentation. However, it is important to note that children usually start understanding what these statements actually mean only after extensive discussions. When teaching a unit based on such a generative theme, teachers should always pay special attention to conscious repetition. This enables children to interpret meaning on their own. According to our experience, children are very much interested in such content-related discussions (Olbrich, 2014).

\section{Child-friendly explanation of essential concepts}

The Rostock model was developed nine years ago and since then it has been tested several times (e.g.: Revákné-Markóczi, 2008). Findings from these pilot studies are always included in current model descriptions. The explicit introduction of central themes ("Hauptbegriff") as didactic principle has been a major innovation. What is the significance of all that? Central themes denote concepts which are essential for students to understand a learning unit. At the same time, teachers assume that children are not familiar with or do not have a firm understanding of these concepts. Focusing on their own classes, teachers identify and describe these themes in a professionally accurate, but still child-friendly language (Weisenfels, 2015: 87; 96; 105). In order to observe the various stages of children's cognitive development, teachers should pay special attention to how they describe these themes. Therefore, they should primarily rely on pseudo concepts, i. e. they should present examples or propose potential definitions by referring to functions (Vygotskij, 2002). In class, teachers then work with these particular descriptions.

\section{Establishing specific learning criteria}

As explained above, classwork is always organized on the basis of themes which were identified in advance and all discussions are continuously guided by learning objectives. The underlying assumption is that is less effective to discuss the learning content „step by step" and to assess progress only at the end. Potential learning resources get lost if assessment is restricted to be a mere conclusion of each unit. Instead, integrating assessment into the learning process by providing regular feedback proves to be far more fruitful. Children are supported in their learning by self-assessment or by receiving 
ongoing feedback from their teachers and their peers. For example, tasks are revised once again after follow-up comments. In other words, this is all about giving every child the hope of improving their performance (Charles, 2000).

Assessment and feedback must have some indicative criteria in order to support the learning process in class. Learning objectives are cornerstones for establishing learning criteria. Teachers are required to establish these assessment criteria as early as the beginning of each unit. "What must students know or be able to accomplish at a certain level? " An accurate indexing of performance levels allows teachers to identify the present and the proximal stage of development for every single child. Consequently, teachers can provide target-oriented support by giving instructions or designing tasks that best suit their children. It is well-known that there can be a productive interaction between cognitive processes and emotions if teachers consider the following aspects when designing the learning process. Children should concentrate on a restricted, well-defined task. Instructions should be clearly formulated and related to each other. Tasks should be followed by clear and comprehensible feedback (Schneider, 2003: 146 etc.).

Just like learning objectives, learning criteria are also established at the beginning of each unit by considering not only teacher's expectations (analysis and assessment toolkit) but also involving the perspective of students. All along the learning process, children are aware of both these criteria and the learning objectives, so they can recognize on their own if and to what extent they have accomplished these objectives. It is highly recommended that the teacher and the children elaborate together these criteria (student's perspective) and children formulate expectations in their own words. For example: „How do I know what I'm already able to do? “- „What are the tasks I cannot complete or I can complete only to some extent? “- „What are those areas where I need some improvement? „ To sum it up, learning criteria

- $\quad$ are discussed and established at the beginning of each unit.

- $\quad$ are strongly connected to learning objectives.

- define a performance level (e.g.: a good performance).

- $\quad$ are highly specific and are formulated in a clear, child-friendly language.

- $\quad$ are reconsidered during the learning unit if necessary.

- $\quad$ are explained by using examples if necessary.

- $\quad$ are either displayed in the classroom or handed out in list format so that every child can look them up any time.

Learning criteria provide children with the chance to take a critical look on their own improvement and to evaluate themselves.

\section{Exploring the learning background}


There are still only few teachers who design their classes with regards to what their students expect. If teachers do rely on children's everyday experiences at the beginning of classes, then they primarily treat these in class discussions as a form of motivation. However, individual experiences can only turn into important learning factors if discursive debates take place. It is an important question how experiences and expectations of students can be deployed in classroom.

As a first step, one can use brainstorming to collect associations. Children talk about their topic-related experiences, thoughts and ideas. Furthermore, the reflection phase at the end of each unit offers valuable insights about how children think. Peer discussion appears to be ideal for both brainstorming activities and for follow-up reflection. As previously mentioned, teachers can get clues to identify the levels of knowledge by observing how children participate in game activities. Children usually play on the borderline between their present and next stage of development. There is a tension between what they are already able to do and what they are not yet (Schneider, 1997: 113). Taking a careful look at what kind of questions children ask about the topic is another way to explore learning conditions, i. e. to find out more about what children already know and are able to do. Questions refer to the next stage of development and indicate that children are aware of the limits of their knowledge and are willing to learn. Even if adults might think the counterpart, children actually never ask questions at random. Especially reform pedagogy looked upon students' questions as a rich source of learning: "In every single moment when children ask questions, they are truly interested in that thing because their mind is simply made for picking up new insights" (Otto, 1965: 11).

By using a combination of visualization (children's drawing) and picture reading, teachers can also get an idea of what and how students think. What concepts students use or do not use and how they establish links may be indicative of their explicit knowledge. Concept mapping can prove to be appropriate for this purpose. This method requires that children establish connections between concepts of a given field and even discover predicative relationships between them (Novack, 1998).

\section{A culture of communicative discussion and inquiry}

The Rostock model aims at making planning and organization of learning units transparent and comprehensible for children. It also targets at an extensive student involvement. Creating a communicative classroom culture with discussions and questions is an essential prerequisite for realizing all that. Children learn to form an opinion, to present their ideas in the group, to listen to others, to refer to statements made by fellowstudents and to find arguments that support their own views. 
Especially topic-related peer discussions make children familiar with a so-called „culture of thoughtfulness"(Kultur der Nachdenklichkeit). Students are gradually encouraged and enabled to engage themselves in discursive forms of discussion (Schneider, 2007: 11). In this context, communicative exchange crucially depends on what questions and presumptions children have. If teachers accept and treat these questions in a respectful manner, then children learn that not understanding something and asking questions are actually very important elements of the learning process. To struggle and to make efforts show that one has learned something new. At this stage, it is essential that children are able to talk about their problems and to ask for help. This is the reason why it is necessary right from the very beginning to create a culture of communicative discussion and inquiry, so that children can take an active part in their own learning processes.

\section{Combination of individual learning, cooperation and instruction}

Within the Rostock model, planning and teaching learning units implies a mutual interdependence of teacher's instructions, independent learning, pair and team work.

As already explained, even in elementary school, learning processes always depend on individual learning. Individual learning takes place both in manual tasks with objects and in tasks that require thinking. Therefore, it is necessary to provide children with the chance to work with objects in everyday situations as much as possible. At the same time, children should also be given enough opportunity to take a critical look at these activities. Not only individual work, but also teacher's instructions play an important role in classroom learning (Hodson, 1998). The human mind is designed to pick up and to process as much information from others as possible. This is especially true about children to a high degree (Gopnik, 2000). How and for what reason? Children want get information which is rooted in the collective memory of a society and which they assume adults know. They would be unable to acquire this knowledge on their own. Teacher's instructions which summarize, explain or elaborate various aspects, enable and help children to structure new information. Speaking of classroom learning, a third key element is cooperation among students. At a particular time, every child reaches a particular level of development in every learning process. For this particular level, Lew Vygotskijj (2002: 327) coined the term level (zone) of present development. However, he argues that this term describes the present level of development insufficiently. In order to exploit the possibilities classroom work offer, it is necessary to determine the next or proximal zone of development in case of each and every child. This way, Vygotskij distinguishes between two different levels according to how children can accomplish tasks with guidance and on their own. Learning something new takes place in the zone of proximal development. Vygotskij refers to this zone as the stage of cooperative learning and ascribes great importance to it: „what children can do with assistance today, they will 
be able to do by themselves tomorrow" (2002: 331). Cooperation within the zone of proximal development should not be restricted to the teacher's assistance only. Parents play an equally important role. Pair and team work in class prove to be effective if tasks are designed according to the particular zone. Social cooperation can have diverse forms and may include both practical and theoretical task formats, pair or group work, discussions with experts and even help from parents. All these forms of class work provide feedback for children and inform them about their performance and perspectives with regards to their learning.

\section{On-going self-assessment and feedback}

Classroom learning will be more successful for children if they have specific guidelines. Furthermore, they also need an appropriate level of individual control and freedom. Teachers should increase this autonomy as students are getting more and more competent. Learning objectives and criteria which are formulated from the students' perspective and are put on display in the classroom, are crucial in this respect because they enable students an ongoing reflection on their own level of development: What can I already accomplish? What do I still struggle with? At the same time, one should also keep in mind that all forms of assessment provide possible guidelines. If teachers evaluate their students' only at the end of a lesson, then many potential learning resources get lost, which would provide an opportunity to evaluate and comment on students' performances.

This is the reason why the Rostock model emphasizes that during the entire learning process children should

- be familiar with learning objectives and criteria and should be encouraged to reflect on these over and over again.

- receive ongoing feedback about their level of development (from the teacher, from fellow students or through self-assessment).

- $\quad$ have the chance to take a critical look at their work every little while.

- learn how to consider mistakes as sources of their further learning.

- $\quad$ have the chance to talk about how they feel about learning.

- have the opportunity to evaluate their own achievements.

From the beginning to the end, children are given the opportunity to talk about their present understanding. Learning processes are designed in a way that children can establish connections between their own experiences and similar actions or situations. Time after time, students are encouraged to explain their intermediate results, to speculate about what would happen or would have happened if the circumstances had been different. Achievements should be assessed not only by using tests but instead evaluation should primarily consist of individual and creative presentations such as posters, collages, exhibitions, talks or essays etc. 


\section{Critical assessment of the learning process}

According to the Rostock model, each learning unit should be concluded with a critical reflection about the learning process. This didactic function can even precede the monitoring phase. Using the learning criteria, children are asked to assess whether and to what degree they have achieved the learning objectives. Once again, they become aware of what they have learned, what they have found interesting, where they had difficulties, how they felt about certain activities and tasks. The ability to recap the learning process, its results and the emotions associated with the whole process contributes to establishing a long-term knowledge.

\begin{tabular}{|c|c|c|}
\hline \multicolumn{3}{|c|}{ Sample questions for critical reflection on the learning process } \\
\hline Cognitive learning objectives & Emotional state & $\begin{array}{l}\text { Hints for teachers to initiate } \\
\text { discussions }\end{array}$ \\
\hline $\begin{array}{l}\text { - What do I know about this } \\
\text { topic? } \\
\text { - Do I understand the topic } \\
\text { now as much as I would like to? } \\
\text { - What questions do I have? } \\
\text { - What is the connection } \\
\text { between my previous } \\
\text { expectations and what I have } \\
\text { learned so far? } \\
\text { - Which tasks were difficult for } \\
\text { me? Which tasks and activities } \\
\text { were good for me? } \\
\text { - What would I change if I had } \\
\text { to do the tasks and activities } \\
\text { once again? } \\
\text { - What or who helped me the } \\
\text { most to understand the topic? }\end{array}$ & $\begin{array}{l}\text { How did it feel when .... } \\
\text { - I solved a task successfully? } \\
\text { - I had difficulties with a task or } \\
\text { activity? } \\
\text { - I asked for help? } \\
\text { - received help? } \\
\text { What classroom atmosphere } \\
\text { helped me the most to learn } \\
\text { new things? } \\
\text { - ... }\end{array}$ & $\begin{array}{l}\text { - What did you find difficult } \\
\text { about this topic? } \\
\text { - How can you use what you } \\
\text { have learned in order to } \\
\text { explain something or to solve a } \\
\text { problem? } \\
\text { - Which social forms made you } \\
\text { feel that you are part of what is } \\
\text { happening? } \\
\text { - What possibilities did you } \\
\text { have to create something new? } \\
\text { - In your opinion, did the class } \\
\text { recognize you and did the } \\
\text { others appreciate } \\
\text { contributions? } \\
\text { - Do your think you worked well } \\
\text { both on your own and with the } \\
\text { others? } \\
\text { - Regarding teamwork, what } \\
\text { should be changed in your } \\
\text { view? }\end{array}$ \\
\hline
\end{tabular}

Thinking about one's own learning is also a competence that has to be trained. Peer discussion is a suitable form for reflection phases. At the beginning, the teacher explains this social form and manages the individual turns by asking thought-provoking questions that structure the discussions. The aim is that the teacher-talking time should be gradually reduced in elementary school. Thinking about the learning processes also makes children understand that they are responsible for their own learning. At the same time, this boosts 
their self-confidence and the teacher can also find out more about what level students have achieved - which is an important prerequisite for planning advanced learning processes.

\section{Strengthening the self- esteem of every single child}

According to the Rostock model, all measures must aim at strengthening the self-esteem of every single child. Self-esteem is defined as a psychological construction, which, based on one's emotions may express a positive or negative self-recognition (Damon, 1989). Self-esteem has its foundations in various emotional experiences which are contrasted on intra- and interpersonal levels and are linked to specific situations and fields of cognition. Later on, these experiences are generalized across time and forms of cognition and are turned into the defining emotional state of a given person (Hauser, 1995). Striving for a positive self-recognition is an essential human need, which consequently determines behavior. Children in elementary school usually express the following needs and wants at school (Charles, 2000): they have a desire for safety, recognition and respect. They hope that in the future they get the chance to improve their performance at school over and over again. They would like to have a degree of control over school activities which they participate in. Children are willing to take part in activities that they enjoy and are rewarding for them. They would like to know and understand things and they want to be able to solve tasks successfully. Last but not least, elementary school children also have a very dominant and innate need for play.

\section{References}

Blíthe, T.(1999). The Teaching for Understanding Guide. San Francisco: Jossey-Bass Publisher.

Charles, C.(2000). The Synergetic Classroom. Joyful Teaching and Gentle Discipline. New York: Longman.

Clarke, S. (2001). Unkocking Formative Assessment. Practical strategies for enhancing pupils' learning in the primary classroom. London: Hodder \& Stougthon.

Damon, W. (1989). Die soziale Entwicklung des Kindes. Ein entwicklungspsychologisches Lehrbuch. [Social development of pupils. A student book of developmental psychology.] Stuttgart: Klett-Cotta.

Goleman, D. (2008). Soziale Intelligenz[Social intelligence.]. München: Knaur TB.

Gopnik, A. (2000). Forschergeist in Windeln. Wie Ihr Kind die Welt begreift. Kreuzlingen. [Researcher mind in diapers. Way of pupils' understanding about the world. Crossnode. ] München: Ariston.

Hauber, K. (1995). Identitätspsychologie. [Psychology of identity.] Berlin: Springer.

Hodson, D. (1998). Teaching and Learning Science. Towards a personalized approach. Buckingham. Philadelphia: Open University Press. 


\section{HERJ Hungarian Educational Research Journal Vol 6 (2016), No 1}

Novack, J. D. (1998). Learning, Creating and Using Knowledge. Concept Map as Facilitative Tools in Schools and Corporations. Mahwah, New Jersey, London: Erlbaum.

Olbrich, J. (2014). Soziales Lernen im Anfangsunterricht - Ärger ist ein schlechter Ratgeber. [Starting of social learning - anger is a bad advisor.] Rostock: Universität Rostock (Examensarbeit) Meyer.

Revákné-Markóczi I., Kosztin-Tóth, B., Tóth Z., Dobóne-Tarai, É. Schneider, I. K., \& Oberlander F. (2008). Effects of the Rostock Model on Metacognitive Development of Pupils. Journal of Science Education, Vol. 9 (2), 94-99.

Spitzer, M. (2004). Selbstbestimmen. Gehirnforschung und die Frage: Was sollen wir tun? Brain research and a question: What should we do?] Heidelberg. Berlin: Spektrum Akad. Verlag.

Schneider, I., K. (1997). Realität und Dialektik des kindlichen Spiels. [Reality and dialectic of pupils' toys.]In E. Renner, S. Riemann, I. K. Schneider, T. Trautmann (Hrsg.), Spiele der Kinder (113-127). Weinheim: Deutscher Studien Verlag.

Schneider, I., K. ( (2003). So sehe ich die Sache! Kinder verstehen - Kinder erziehen. Baltmannsweiler: Schneider Verl. Hohengehren. (I See the Things this Was: Understanding and Educating Children. German)

Schneider, I., K. ( (2007). Politische Bildung in der Grundschule. [Education in elementary school.] Baltmannsweiler: Schneider Verl. Hohengehren.

Schneider, I., K. (2008a). Naturwissenschaftliches Lernen in der Grundschule. [Science learning at primary level. ] Baltmannsweiler: Schneider Verl. Hohengehren.

Schneider, I., K. (2008b). Experimente für kleine Forscher. [Experiments for young researchers.] Donauwörth: Auer Verlag.

Vygotskij, L. S. (2002). Denken und Sprechen. [Thinking and tongue.]Weinheim, Basel: Beltz TB.

Weissenfels, I. K. (2015). Soziales Lernen im Anfangsunterricht. [Social Learning of School Starters. German.) Stuttgart: Kohlhammer. 